\title{
Erratum to: Evaluation of variants in the CHEK2, BRIP1 and PALB2 genes in an Irish breast cancer cohort
}

\author{
N. M. McInerney $\cdot$ N. Miller $\cdot$ A. Rowan • \\ G. Colleran · E. Barclay $\cdot$ C. Curran · M. J. Kerin • \\ I. P. Tomlinson $\cdot$ E. Sawyer
}

Published online: 29 March 2011

(C) Springer Science+Business Media, LLC. 2011

Erratum to: Breast Cancer Res Treat (2010)

121(1):203-210

DOI 10.1007/s10549-009-0540-9

Author would like to add the below mentioned acknowledgement:

IT was funded by the Oxford Comprehensive Biomedical Research Centre.

The online version of the original article can be found under doi:10.1007/s10549-009-0540-9.

N. M. McInerney $(\bowtie) \cdot$ N. Miller · G. Colleran · C. Curran ·

M. J. Kerin

Department of Surgery, Clinical Science Institute,

University College Hospital, Galway, Ireland

e-mail: nmac@ymail.com

N. M. McInerney · A. Rowan · G. Colleran · E. Barclay ·

I. P. Tomlinson · E. Sawyer

Molecular and Population Genetics Laboratory, Wellcome Trust,

Centre for Human Genetics, University of Oxford, Roosevelt

Drive, Oxford OX3 7BN, UK

E. Sawyer

Guy's, King's, St. Thomas' Cancer Centre, Guy's Hospital,

St. Thomas's Street, London SE1 9RT, UK 